Clearly most children with ALL have a single chance of cure at the time of diagnosis, and no effort must be spared to ensure optimum treatment from the start to prevent relapse and not merely to postpone it. More-aggressive conventional chemotherapy will probably not substantially improve the outcome in patients who have already had a marrow relapse during treatment. It is in such patients that new therapeutic approaches such as bone-marrow transplantation ${ }^{9}$ are justifiable.

Meanwhile, in children who have a marrow relapse during treatment the benefits of achieving a second remission lasting a median of three months should perhaps be weighed against the cost to the child and his family in terms of discomfort, hospital attendance, and admissions. In these children above all others the major consideration should be the quality of life.

\section{References}

${ }^{1}$ Gribbin, M, Hardisty, R M, and Chessells, J M, Archives of Disease in Childhood, 1977, 52, 673.

2 Medical Research Council's Working Party on Leukaemia in Childhood, British fournal of Haematology, 1976, 33, 179.

${ }^{3}$ Medical Research Council's Working Party on Leukaemia in Childhood, in preparation.

${ }^{4}$ Aur, R J A, et al, New England fournal of Medicine, 1974, 291, 1230.

${ }^{5}$ Rivera, G, et al, Cancer, 1976, 37, 1679.

${ }^{6}$ Medical Research Council's Working Party on Leukaemia in Childhood, British Medical fournal, 1971, 4, 189.

${ }^{7}$ Aur, R J A, et al, Cancer, 1972, 30, 334.

${ }^{8}$ Leventhal, B G, et al, Cancer, 1975, 35, 1136

9 Thomas, E D, et al, Blood, 1977, 49, 511.

\title{
Prevention of $\mathrm{Rh}$ haemolytic disease
}

\section{A D TOVEY, JANE MURRAY, BERYLL J STEVENSON, J M TAVERNER}

British Medical fournal, 1978, 2, 106-108

\section{Summary and conclusions}

Between 1970 and 1976 in the Yorkshire region the incidence of $R h$ antibodies in $R h$-negative pregnant women fell by $70 \%$. This decrease occurred in both old (long-standing) and new (first-affected) cases, which emphasised that the reduction in numbers was as much due to fewer pregnancies among Rh-negative mothers as to administration of anti-D immunoglobulin. Nevertheless, the incidence has begun to level out. The continued incidence of first-affected cases is caused by three main factors: failure of administration of anti-D immunoglobulin after normal deliveries and abortions; a steady incidence of antibodies in primigravidae; and cases in which administration of anti-D immunoglobulin had failed to protect.

Administering anti-D antenatally might reduce the incidence of new cases among primigravidae who are sensitised before anti-D is normally given. Even without routine antenatal administration of anti-D, the incidence of severely affected $\mathrm{Rh}$ babies in the Yorkshire region could be reduced to one or two isolated cases a year in a population of three to four million by administering anti-D after all $\mathrm{Rh}$-negative deliveries and after every abortion.

\section{Introduction}

During the past few years there has been a dramatic fall in the incidence of $\mathrm{Rh}$ haemolytic disease. ${ }^{2}{ }^{2}$ This is due to two factors, firstly the appreciable fall in the number of Rh-negative women having babies, particularly if they had developed $\mathrm{Rh}$ antibodies previously; and secondly the routine administration of anti-D

Regional Transfusion Centre, Leeds LS15 7TW

L A D TOVEY, MD, FRCPATH, director

JANE MURRAY, BSC, MB, clinical assistant

BERYLL J STEVENSON, $\mathrm{MB}$, CHB, clinical assistant

J M TAVERNER, BSC, senior scientific officer immunoglobulin to Rh-negative women delivered of Rh-positive infants.

We describe the present position of $\mathrm{Rh}$ prophylaxis in an area of Yorkshire with a population of three and a half million and 44000 births a year, and discuss the measures available to reduce the incidence of $\mathrm{Rh}$ haemolytic disease still further.

\section{Present study}

OVERALL INCIDENCE OF BLOOD-GROUP ANTIBODIES 1970-6

From 1970 to 1976 the incidence of $\mathrm{Rh}$ antibodies in $\mathrm{Rh}$-negative women decreased by $70 \%$, the incidence of non- $\mathrm{Rh}$ antibodies in $\mathrm{Rh}$-negative women by $35 \%$, and that of antibodies in Rh-positive women by $19 \%$ (table I).

FACTORS INFLUENCING INCIDENCE OF RH ANTIBODIES IN RH-NEGATIVE WOMEN

If the fall in the incidence of $\mathrm{Rh}$ antibodies was primarily due to administration of anti-D immunoglobulin the incidence of "firstaffected" pregnancies (those in which antibodies were detected for the first time) should show a dramatic fall in incidence compared with "long-standing" cases. Our results show that this is not so (see table II). Between 1970 and 1976 the incidence of first-affected cases

TABLE I-Blood-group antibodies in pregnant women 1970-6

\begin{tabular}{|c|c|c|c|c|c|c|c|}
\hline & 1970 & 1971 & 1972 & 1973 & 1974 & 1975 & 1976 \\
\hline \multicolumn{8}{|c|}{ Rh-negative mothers } \\
\hline $\begin{array}{l}\text { No with anti-D, } C+D, \\
D+E, \text { and } C+D+E \\
\text { No with other antibodies }\end{array}$ & $\begin{array}{r}481 \\
26\end{array}$ & $\begin{array}{r}428 \\
24\end{array}$ & $\begin{array}{r}368 \\
28\end{array}$ & $\begin{array}{r}285 \\
34\end{array}$ & $\begin{array}{r}201 \\
24\end{array}$ & $\begin{array}{r}178 \\
17\end{array}$ & $\begin{array}{r}144 \\
17\end{array}$ \\
\hline \multicolumn{8}{|c|}{ Rh-positive mothers } \\
\hline No with antibodies & 111 & 110 & 111 & 100 & 117 & 79 & 90 \\
\hline
\end{tabular}

TABLE II-Numbers of women delivered with anti-D and ant $-D+C$ antibodies, and numbers of first-affected and long-standing cases, 1970-6*

\begin{tabular}{l|c|c|c|c|c|c}
\hline & 1970 & 1972 & 1973 & 1974 & 1975 & 1976 \\
\hline $\begin{array}{l}\text { Total No with anti-D and } \\
\text { anti-D +C }\end{array}$ & 469 & 346 & 278 & 195 & $\begin{array}{c}171 \dagger \\
65\end{array}$ & $\begin{array}{c}134 \\
60\end{array}$ \\
$\begin{array}{l}\text { No of first-affected cases } \\
\text { No of long-standing cases }\end{array}$ & 202 & 143 & 117 & 78 & 105 & 74 \\
\hline
\end{tabular}

*Data unavailable for 1971

tInsufficient information available on one patient to allow classification. 
fell by $70^{\circ}$ and that of long-standing cases by $72 \%$. To discover why the fall in first-affected cases was not greater we examined the case histories of all new cases between 1974 and 1976 in more detail, and tried to explain why the patient developed anti-D or anti-C+D. Patients were grouped according to whether the cause was "possibly avoidable" or "probably unavoidable" (table III).

TABLE III-Analysis of first-affected cases, 1974-6, according to factor influencing development of $R h$ antibodies

\begin{tabular}{|c|c|c|c|}
\hline & 1974 & 1975 & 1976 \\
\hline \multicolumn{4}{|c|}{ Possibly avoidable causes } \\
\hline $\begin{array}{l}\text { Anti-D not given after abortion } \\
\text { Records showed that anti-D } \\
\text { should have been given, but } \\
\text { had not }\end{array}$ & 14 & 8 & 14 \\
\hline \multicolumn{4}{|c|}{ Probably unavoidable causes } \\
\hline $\begin{array}{l}\text { Primigravidae } \\
\text { Mother sensitised before anti-D } \\
\text { was available } \\
\text { Prophylaxis failed }\end{array}$ & $\begin{array}{l}11 \\
23 \\
11\end{array}$ & $\begin{array}{l}10 \\
25 \\
10\end{array}$ & $\begin{array}{r}9 \\
16 \\
14\end{array}$ \\
\hline
\end{tabular}

\section{POSSIBLY AVOIDABLE FACTORS}

There was a continuing steady incidence of new cases in which anti-D immunoglobulin had not been administered after abortion. The incidence of first-affected cases in which the patients' records showed that anti-D immunoglobulin should have been given, but was not, fell between 1974 and 1975, but had levelled out by 1976 . Several reasons ${ }^{1}$ may explain why anti-D immunoglobulin had not been given. In most, either the laboratory did not receive cord samples from the babies of Rh-negative mothers or the clinicians did not act on the results. A further reason why anti-D immunoglobulin was not administered was shown in the analysis of cases occurring in 1975-6. In two instances anti-D was detected in high titres in the sera of pregnant women. It was found that anti-D immunoglobulin had not been given after a previous pregnancy, since the laboratory had reported the infants to be $\mathrm{Rh}$-negative. Subsequent tests showed that the children were $\mathrm{Rh}$-positive. This error could not be explained, though the "cord" sample tested may actually have been maternal blood. This has happened once or twice in other clinical circumstances. The laboratories concerned now test all "cord" blood samples for fetal haemoglobin to exclude this unfortunate source of error.

\section{PROBABLY UNAVOIDABLE FACTORS}

There was a steady incidence of $\mathrm{Rh}$ antibodies in primigravidae in 1974-6, and the numbers of women who were sensitised before anti-D immunoglobulin was available continued to fall slowly.

\section{Failures of protection}

In 1974-6 there were 35 pregnancies in which an injection of anti-D immunoglobulin after the previous pregnancy had failed to protect. A failure occurs when a mother develops an anti-D antibody detected by any technique (enzyme, albumin, indirect antiglobulin, or saline) at any time in a subsequent pregnancy after receiving anti-D immunoglobulin. ${ }^{3}$ In 21 of these 35 cases the antibody was detected only towards the end of the subsequent pregnancy, but the antibody titre was usually very weak, and only three infants required exchange transfusion. The cord or capillary haemoglobin concentrations at birth ranged from $11.5 \mathrm{~g} / \mathrm{dl}$ to $19.0 \mathrm{~g} / \mathrm{dl}$. In eight instances the antibody was detected early in the subsequent pregnancy. The highest titre reached during the pregnancy was $15 \mathrm{IU}$, apart from one case, in which the titre rose to 70 IU. The cord/capillary haemoglobin concentrations ranged from $6.4 \mathrm{~g} / \mathrm{dl}$ to $16.9 \mathrm{~g} / \mathrm{dl}$, and four infants required exchange transfusion. All made satisfactory progress. In one instance the mother attended her first antenatal clinic at 34 weeks and was found to be weakly positive for anti-D antibody (titre $<1$ IU). She was delivered at 40 weeks, when the cord haemoglobin concentration was $6.4 \mathrm{~g} / \mathrm{dl}$. Exchange transfusion was performed and the child made satisfactory progress.

One case ended in a stillbirth at 40 weeks. The highest titre reached before the death of the fetus was 5 IU and the pathologist reported after the necropsy that death had been "due to intrauterine anoxia, no stigmata of Rh incompatibility found." The remaining four mothers were delivered of Rh-negative infants. Outcome was generally successful in the infants who were not protected during 1974-6, as in previous years, ${ }^{3}$ apart from the one stillbirth, which was probably not due to $\mathrm{Rh}$ antibodies.

\section{FAILURE RATE}

Table IV shows the number of failures of protection after anti-D administration compared with the number of subsequent pregnancies in which the infants were unaffected. During 1974-6 the failure rate remained constant at about $0.9 \%$. This seemed to be unrelated to the dose of anti-D immunoglobulin given (table V), 100- $\mu \mathrm{g}$ doses appearing to be as successful as doses of $200 \mu \mathrm{g}$ and more in protecting mothers. At present we have insufficient information to be dogmatic about the efficiency of the 50- $\mu \mathrm{g}$ dose. Most 50- $\mu \mathrm{g}$ doses are given after abortion, and so far two failures of protection in a subsequent pregnancy have occurred. One failure followed the administration of a $50-\mu \mathrm{g}$ dose after an amniocentesis early in pregnancy for genetic reasons. The antibody persisted and the infant was mildly affected.

TABLE IV-Number of pregnancies in Rh-negative women after administration of anti-D immunoglobulin 1974-6, and number in which anti-D failed to protect against development of $R h$ antibody

\begin{tabular}{c|c|c|c|c|c}
\hline \multirow{3}{*}{ Year } & \multicolumn{2}{|c|}{ Dose of anti-D injected $(\mu \mathrm{g})$} & $\begin{array}{c}\text { Total No of } \\
\text { pregnancies }\end{array}$ & $\begin{array}{c}\text { No }(\%) \text { of } \\
\text { failures }\end{array}$ \\
\cline { 2 - 5 } & 200 & 100 & 50 & & \\
\hline 1974 & 329 & 1005 & 30 & 1364 & $11(0 \cdot 88)$ \\
1975 & 164 & 914 & 51 & 1129 & $10(0.88)$ \\
1976 & 95 & 1271 & 99 & 1465 & $14(0.95)$ \\
\hline
\end{tabular}

TABLE $\mathrm{v}-$ Failure rate in relation to anti-D dose

\begin{tabular}{l|c|c|c}
\hline Anti-D dose $(\mu \mathrm{g}):$ & 200 & 100 & 50 \\
\hline $\begin{array}{c}\text { No of subsequent pregnancies } \\
\text { No }(\%) \text { of failures }\end{array}$ & $\begin{array}{c}1095 \\
8(0.73)\end{array}$ & $\begin{array}{c}3759 \\
31(0.82)\end{array}$ & $\begin{array}{c}191 \\
3(1.57)^{*}\end{array}$
\end{tabular}

*Anti-D given after abortion (two cases) or after amniocentesis (one case).

\section{Discussion}

Although the number of cases of $\mathrm{Rh}$ haemolytic disease has fallen steadily during the past few years, the rate of fall is declining. The reasons for this levelling out are clear from our study. Cases encountered today are either long-standing-that is, those in which the mother had become sensitised before anti-D immunoglobulin was available-or first-affected, new cases. Long-standing cases will continue to decline in numbers, but, as a woman may have a span of 30 childbearing years, the decline will be steady but prolonged. New cases occur in three ways. The mother may be eligible to receive anti-D immunoglobulin, but fails to receive the injection (the "administrative failure"); the mother may have become sensitised before she receives the anti-D immunoglobulin; or, what may well be the same state of affairs, the mother fails to be protected by the anti-D injection.

The continuing incidence of administrative failures is worrying. Some reasons why mothers failed to receive an injection after delivery have been described elsewhere. ${ }^{1}$ Since that report further investigations have shown that in some instances the mother failed to receive a prophylactic injection because the infant had been wrongly grouped as Rh-negative. These types of administrative failures could well be reduced if all $\mathrm{Rh}$-(D)-negative women received an injection of anti-D immunoglobulin after delivery, irrespective of the infant's $R h$ group; but this would mean that the amount of anti-D immunoglobulin used would increase by about $70 \%$.

Preventing sensitisation after abortion is more difficult. It should be straightforward if the woman has a therapeutic abortion, but is much more difficult if this is spontaneous. ${ }^{4}$ The mother may not be aware of her blood group or even that she is 
aborting. Hence the incidence of post-abortion sensitisation probably cannot be eliminated. Nevertheless, much can be done to reduce the number of cases appreciably. Surprisingly, many doctors are still unaware that anti-D immunoglobulin should be administered in these cases. Occasionally it is difficult to pinpoint the time of the abortion. Samson and Mollison, ${ }^{5}$ however, found that administering anti-D immunoglobulin up to 13 days after an injection of $\mathrm{Rh}$-positive cells was effective in preventing sensitisation. Anti-D immunoglobulin should be given even at this late stage after a possible abortion. Roughly 20 cases a year of post-abortion or administrative failures of protection occur in the Yorkshire region-that is, a third of all new cases. If this region is typical eliminating these cases would greatly reduce the total incidence in Great Britain.

Primigravidae who are sensitised before anti-D immunoglobulin is normally administered make up most cases of socalled failures of protection. Several centres have instituted a programme of antenatal administration of anti-D immunoglobulin, which is also being actively considered in Great Britain. Regimens vary from one dose, usually at 28 weeks, as in the Hamilton (Canada) series and a Swedish series, to a twodose regimen usually at 28 and 34 weeks in an Australian programme and the Manitoba project (unpublished data). Preliminary "results suggest that antenatal administration of anti-D immunoglobulin reduces the incidence of antibodies detected at six months after delivery, but it is too early to be certain that it reduces the number of sensitised mothers in subsequent pregnancies. If it is shown that antenatal injection does reduce the incidence of sensitisation the incidence in the Yorkshire region would decrease by 20 to 30 cases a year. If this again is typical it would mean a decrease of 300-400 cases a year in Great Britain. Nevertheless, it would entail administering three times as much anti-D immunoglobulin as at present, a costly enterprise. Moreover, the number of new cases might be similarly reduced by administering anti-D immunoglobulin after all $\mathrm{Rh}$-negative deliveries and after every abortion.

One of our findings is of theoretical as well as practical interest. The fall in the incidence of $\mathrm{Rh}$ antibodies in $\mathrm{Rh}$ negative women was $70 \%$; the fall in the incidence of $\mathrm{Rh}$ positive mothers with antibodies was $19 \%$, which presumably reflects the fall in the number of women having babies. Nevertheless, the fall in the number of Rh-negative women with non$\mathrm{Rh}$ antibodies was $35 \%$. This suggests that anti-D immunoglobulin may have a non-specific effect, and supports the thesis of Woodrow and others in Liverpool ${ }^{6}$ that the mechanism of anti-D immunoglobulin protection is not antigen-specific. More data on this topic are needed.

We thank all obstetricians in the region for their help and cooperation, and for willingly making available the notes of the patients concerned; and the clerical staff for patiently obtaining the information required.

Requests for reprints should be addressed to Dr L A D Tovey, Yorkshire Regional Transfusion Centre, Bridle Path, Leeds LS15 7TW.

\section{References}

1 Tovey, L A D, Health Trends, 1976, 8, 25.

${ }^{2}$ Freda, V J, Gorman, J G, and Pollock, W, American Fournal of Obstetrics and Gynecology, 1976, 28, 456.

3 Tovey, L A D, and Robinson, Angela A, British Medical fournal, 1975, 4, 320.

${ }^{4}$ Grimes, D A, Ross, W C, and Hatcher, R A, Obstetrics and Gynecology, 1977, 50, 261.

5 Samson, Diane, and Mollison, P L, Immunology, 1975, 25, 349.

${ }^{6}$ Woodrow, J C, et al, British Medical fournal, 1975, 2, 57.

(Accepted 15 March 1978)

\section{Today's Treatment}

\section{Use of antibiotics}

\section{Antifungals}

\section{R Y CARTWRIGHT}

\section{B ritish Medical fournal, 1978, 2, 108-111}

An increasing number of specific antifungal agents are now available for treating patients with fungal infections. It is important that these drugs are used wisely to reduce the emergence of resistant strains-a familiar problem with antibacterial agents. Many of the new antifungals are suitable for treating both superficial and deep mycoses. The management of a patient with a fungal infection, however, may not depend on specific antifungals, as the infections, especially those that are deep seated, may be secondary to another disease. Failure to recognise and control the underlying factors may result in the apparent failure of an antifungal agent. Another cause of

Public Health Laboratory, St Luke's Hospital, Guildford GU1 3NT R Y CARTWRIGHT, MB, MRCPATH, consultant microbiologist failure to control many deep-seated mycoses is that they are not diagnosed early in the disease. Not only should underlying factors be considered in fungal diseases but in patients with recognised predisposing factors the possibility of a fungal infection must be remembered.

The diagnosis of a fungal infection should whenever possible be established by microscopy, culture, or serology before treatment starts. I cannot consider all antifungals in detail in this article, but I will discuss the main groups of antifungal drugs and their application to treating the commoner fungal infections in Britain.

\section{Griseofulvin}

Griseofulvin (Fulcin, Grisovin) is a unique antimicrobial agent that is absorbed from the gastrointestinal tract and is then selectively concentrated in a single tissue-keratin-where it 